\title{
WILEY-VCH
}

DOI: $10.1002 /$ ((please add manuscript number))

Article type: Full Paper

\section{In situ Production of Biofunctionalized Few-Layer Defect-Free Microsheets of Graphene}

Alfredo M. Gravagnuolo ${ }^{\ddagger}$ Eden Morales-Narváez $z^{\ddagger}$, Sara Longobardi, Everson T. da Silva, Paola Giardina and Arben Merkoçi*

A. M. Gravagnuolo, Dr. E. Morales-Narváez, E.T. da Silva, Prof. A. Merkoçi ICN2 - Catalan Institute of Nanoscience and Nanotechnology, 08193 Barcelona, Spain

A. M. Gravagnuolo, Dr. S. Longobardi, Prof. P. Giardina

Department of Chemical Sciences, University of Naples "Federico II", 80126 Naples, Italy

Prof. A Merkoçi

ICREA - Catalan Institution for Research and Advanced Studies, 08010 Barcelona, Spain

*These authors contributed equally.

E-mail: arben.merkoci@icn.cat

Keywords: graphene production, biofunctionalized graphene, self-assembling, bionanotechnology

Biological interfacing of graphene has become crucial to improve its biocompatibility, dispersability and selectivity. However, biofunctionalization of graphene without yielding defects in its $\mathrm{sp}^{2}$-carbon lattice is a major challenge. Here, we set out a process for biofunctionalized defect-free graphene synthesis through the liquid phase ultrasonic exfoliation of raw graphitic material assisted by the self-assembling fungal hydrophobin Vmh2. This protein (extracted from the edible fungus Pleurotus ostreatus) is endowed with peculiar physico-chemical properties, exceptional stability and versatility. The unique properties of $\mathrm{Vmh} 2$ and, above all, its superior hydrophobicity and stability allows us to obtain a highly concentrated $\left(\sim 440-510 \mu \mathrm{g} \mathrm{mL}^{-1}\right)$ and stable exfoliated material ( $\zeta$-potential, $+40 \div+70 \mathrm{mV})$. In addition controlled centrifugation enables the selection of biofunctionalized few-layer defect-free micro graphene flakes, as assessed by Raman spectroscopy, AFM, SEM and electrophoretic mobility. This biofunctionalized product represents a high value added material for the emerging applications of graphene in the 


\section{WILEY-VCH}

biotechnological field such as sensing and drug delivery.

\section{Introduction}

Due to its extraordinary structure and fascinating properties, graphene is definitely the most studied nanomaterial. ${ }^{1}$ Being the thinnest object ever known, graphene is a single layer of carbon atoms patterned in a two-dimensional honeycomb network. ${ }^{[2]}$ As the fundamental building block of carbon allotropes, it exhibits unparalleled properties such as high planar surface $\left(\sim 2630 \mathrm{~m}^{2} \mathrm{~g}^{-1}\right),{ }^{3}$ superlative mechanical strength (Young's modulus, $\left.\sim 1100 \mathrm{GPa}\right),{ }^{[4]}$ remarkable thermal ${ }^{[5]}$ and electrical conductivity ${ }^{[6]}\left(5000 \mathrm{~W} \mathrm{~m}^{-1} \mathrm{~K}^{-1}\right.$ and $1738 \mathrm{~S} \mathrm{~m}^{-1}$, respectively), high absorption of incident white light $(2.3 \% \text {, in spite of its thickness })^{[7]}$, highly efficient fluorescence quenching capabilities $^{[8]}$ and impermeability to standard gases. ${ }^{[9]}$ Consequently, graphene can be integrated as the core of cutting-edge technologies and devices related to photonics, electronics, composite materials, sensors, environment, energy, biotechnology and biomedicine. ${ }^{[10-13]}$

Since the groundbreaking discovery of the surprising properties of graphene, ${ }^{[14]}$ the industrial and scientific communities have focused their attention on the development of new graphene synthesis methods enabling a variety of options in terms of oxidation grade, number of layers, edge and basal defects, lateral size, quality and cost for any particular application. ${ }^{[10,15,16]}$ According to the literature, ${ }^{[10,15]}$ the most relevant routes for graphene generation are the chemical vapor deposition, epitaxial growth, mechanical cleavage, wet chemical synthesis and exfoliation of graphite.

Generally, liquid-phase exfoliation of graphite entails the use of ultrasonication as a key method which promotes the generation of laminated material that is subsequently bound to aggregate due to the lack of hydrophilic groups onto the exfoliated material. ${ }^{[19]}$ In fact, 


\section{WILEY-VCH}

re/aggregation is one of the main challenges to address during the exfoliation procedure and the stabilization of solvent-dispersed graphene flakes ${ }^{[20]}$. However, re/aggregation is typically minimized by using organic solvents with suitable characteristics ${ }^{[21]}$ or surfactant-water solutions. $^{[22,23]}$

Biological interfacing of graphene has become crucial to improve its biocompatibility, ${ }^{[24]}$ dispersibility and selectivity towards various applications in the biotechnological and biomedical fields. ${ }^{[25-27]}$ However, since chemical functionalization of graphene is generally known to sensitively disrupt its electronic structure, ${ }^{[28]}$ the biofunctionalization of graphene without triggering defects, e.g. disrupting the $\mathrm{sp}^{2}$-carbon lattice by introducing oxygencontaining groups, is a major challenge. Although graphene modification and biofunctionalization is under active research, ${ }^{[25]}$ the in situ production of biofunctionalized defect-free graphene has been little explored.

Because of their huge range of functions and high responsiveness to a variety of stimuli, proteins are suitable candidates for bioconjugation of nanomaterials for biomedical applications. Protein binding onto pristine carbon lattice is strongly driven by hydrophobic interactions. ${ }^{[29]}$ Besides hydropathicity character of amino acid residues, three-dimensional protein structure also plays a key role in their adsorption onto graphene-based materials (GBMs) and functionality of the resulting bio-conjugates. For instance, proteins prone to form amyloid structures strongly interact with carbon nanomaterials, forming bio-inspired hybrid materials which show special properties and bio-degradability. ${ }^{[30-32]}$

The use of amphiphilic proteins called hydrophobins from fungal sources has been reported to enable the coating of a wide variety of materials included carbon based materials. ${ }^{[33-36]}$ Hydrophobins are small surface active proteins which play special roles at some stages in the 


\section{WILEY-VCH}

growth and the development of filamentous fungi, ${ }^{[37]}$ being able to self-assemble at hydrophilic-hydrophobic interface to form amphiphilic (mono)-layers. Conventional soluble proteins confine hydrophobic residues in the core of the molecular structure and expose the hydrophilic ones to the solvent to reach a minimum of energy in aqueous environment. Conversely, the Janus-faced character of hydrophobins is due to the clustering of hydrophobic residues on one side of the protein surface maximizing the area of interaction with hydrophobic materials. Consequently, these peculiar proteins can tune the wettability of surfaces and improve their properties for biomedical applications such as sensing and drug delivery. ${ }^{[38-42]}$ Moreover, the hydrophobin coating can confer special properties, i.e. prevention of human immune response, [43] specific functionalities trough protein engineering $^{[34]}$ or molecular adsorption ${ }^{[44]}$.

The hydrophobin family is split in two classes on the basis of their structure and function; ${ }^{[37]}$ class I hydrophobins have natural propensity to self-assemble into remarkably stable amyloid-like nano-structures also known as rodlets, which can only be solubilzed in harsh acids. ${ }^{[45-49]}$ Despite the superior stability of coating by Class I hydrophobins, technologies based on their use have been less exploited with respect to the Class II, possibly because of their lower solubility and high propensity to self-assemble which cause several drawbacks in their handling.

Recently, Laaksonen et al. have demonstrated a one-step approach for the ultrasonic wavebased exfoliation and functionalization of layered carbon materials using Class II hydrophobins from the filamentous fungus Trichoderma reesei. According to the model proposed by Laaksonen and colleagues, self-assembling hydrophobins at solvent-carbon interface tune the surface energy of the two-dimensional carbon lattice in a surfactant-like 


\section{WILEY-VCH}

system, thus reducing the inter-layer stacking which is the driving force opposing to micromechanical exfoliation.

Class I hydrophobin, Vmh2 from the edible white-rot fungus Pleurotus ostreatus, has been purified and extensively studied by our research group. ${ }^{[50,51]}$ Solvent polarity, $\mathrm{pH}$, temperature and the presence of calcium ions trigger the protein transition across structural states. Vmh2 self-assembling into nano-metric films has been explored ${ }^{[52,53]}$ as well as its capability to recruit bio-molecules, such as glucose or a variety of enzymes in their active form, onto the bio-hybrid surface. ${ }^{[44,54]}$ Moreover, surface (silicon and steel) functionalization by Vmh2 has been demonstrated to leave unaltered the optical properties and to be effective in technological devices. ${ }^{[53,55,56]}$

Herein, we explore the ultrasonication-based production of biofunctionalized graphene using the Vmh2 hydrophobin. As depicted in Figure 1, we exfoliate a low-cost graphite source (Graphite powder, Aldrich 332461) in ethanol-water media by a medium power (125 Watt, 20kHz. Inbuilt power meter power output $19 \mathrm{~W}$ ) tip sonicator. Controlled centrifugation (final steps at $620 \mathrm{~g}$ and $2500 \mathrm{~g}$ ) enables us to obtain suspensions of particles of controlled size. They are endowed with exceptional stability in liquid (ethanol-water) due to the hydrophobin coating. Since on one hand the number of graphene layers and their defects significantly modulate the succeeding transport properties, ${ }^{[57]}$ and on the other hand the lateral dimension size controls the maximum dimension and degree of deformability of the material that are paramount parameters for biological interactions, ${ }^{[58,59]}$ we systematically study the quality of the generated graphene sheets in terms of lateral dimension, number of layers per flakes and defect characteristics. To this aim we exploit recent advances in graphene Raman spectroscopy in terms of spectral analysis of $\mathrm{GBMs}^{[60]}$ and study the self-assembled biohybrid structures by AFM, SEM and electrokinetic analysis. 


\section{WILEY-VCH}

\section{Results and Discussion}

\subsection{In situ Exfoliation, Functionalization and Stabilization of GBMs by Vmh2 hydrophobin}

Ultrasonication of graphite powder $\left(1000 \mu \mathrm{g} \mathrm{mL}^{-1}\right)$ in $\mathrm{Vmh} 2$ hydrophobin solution (50-100 $\mu \mathrm{g} \mathrm{mL}^{-1}$ in $60 \%$, v/v, ethanol in water, $5 \mathrm{~mL}$ volume) resulted in dark and stable dispersions of carbon material, see Figure 2A, b. When micromechanical exfoliation was attempted in the absence of the surface active protein, flocculation and settling out occurred in 3 days owing to inter-layer stacking of newly formed flakes, see Figure 2A, a. Scanning Electron Microscopy (SEM) imaging shed light on the starting material, crystallites of $\sim 1 \mathrm{~mm}$ lateral size (Figure 2B), and on the product of $\mathrm{Vmh} 2$ assisted exfoliation/stabilization, an heterogeneous mix of GBMs in terms of particles size (up to $2 \mu \mathrm{m}$ ) and shape, see Figure $2 \mathrm{C}$,.

Aiming at estimating the amount of GBMs attainable by the Vmh2-assisted exfoliation, the un-exfoliated graphite was removed by gentle centrifugation, $40 \mathrm{~min}$ at $40 \mathrm{~g}$, then, UV-Vis measurements ${ }^{[22,34]}$ indicated a concentration of $\sim 440-510 \mu \mathrm{g} \mathrm{mL}^{-1}$ of carbon dispersion. This value was one order of magnitude higher than that one previously reported by Laaksonen and colleagues using class II hydrophobins. In addition, they have employed high-class graphitic sources (HOPG and Kish graphite, which are expensive when compared with graphite powder: Kish graphite $\sim 350$ USD, 0.5g; HOPG $\sim 200$ USD, mosaic of $5 \times 5 \mathrm{~mm}$, thickness 2.0 $\mathrm{mm}$; Graphite powder, $72.8 \mathrm{USD}, 2.5 \mathrm{Kg}$ ) in $0.3-1 \mathrm{~mL}$ volumes of water solutions, obtaining a $25-40 \mu \mathrm{g} \mathrm{mL}^{-1}$ suspension of exfoliated material. ${ }^{[34]}$ In spite of the considerable differences in the geometry of the proposed processes (see Table S1), we believe that the unique properties of $\mathrm{Vmh} 2$ and, above all, its superior hydrophobicity and stability (as described below), play a significant role in such an advance. 


\section{WILEY-VCH}

Sequence analysis of hydrophobins and soluble standard proteins with different physicochemical and functional characteristics evidenced that: (i) hydrophobins show major contribution of hydrophobic amino acids with respect to the other soluble proteins; (ii) Vmh2 is the most hydrophobic hydrophobin among those that have been used for the stabilization of nanomaterials to date (see Figure S1 at supporting information, SI, section). To give insight into its amphiphilic character, the sequence of $\mathrm{Vmh} 2$ was compared with that of hydrophobin HFBI used by Laaksonen and colleagues. Hydropathy analysis suggested that Vmh2 brings into play very extended hydrophobic patches that could strongly drive Vmh2 onto GBMs surface, see Figure S2.

Usually stability to physical and chemical factors deeply limits the use of biological molecules in cutting-edge technology approaches. Irreversible conformational transitions commonly lead to loss of function and aggregation of proteins, often in a temperature dependent kinetics. In contrast, mature $\operatorname{Vmh} 2$ is a small (87 amino-acids) and compact protein, particularly resistant to chemical and physical treatments. ${ }^{[53]}$ It is worth mentioning that partial protein unfolding has been reported to occur at $80^{\circ} \mathrm{C}$, however the protein re-folds by lowering the temperature at $25^{\circ} \mathrm{C} .{ }^{[50]}$ Moreover batches of $\mathrm{Vmh} 2$ protein dissolved in $60 \%$ Vol. ethanol solution were soluble and functional at least 18 months at room temperature. This very stable state has been achieved by using a low polar solvent able to solvate the extended hydrophobic patches exposed on the surface of protein. Vmh2 protein showed extreme resistance also in our system, where intensive ultrasonication causes heating of the solution. Likewise, GBM dispersions were stable for at least 6 months at room temperature.

It should be remarked that $\mathrm{Vmh} 2$ was also able to stabilize carbon dispersions from different graphite sources by adding the protein either before (see Figure S3 left), or after exfoliation. Vmh2-assisted ultrasonication of HOPG as well as addition of Vmh2 to a 


\section{WILEY-VCH}

previously exfoliated HOPG or to a commercial GBM allowed the improvement of their dispersibility and their use for surface functionalization. Indeed, drop casting of the obtained dispersions resulted in a very homogenous coating of silicon chips upon solvent evaporation as shown by SEM imaging, see Figure S3 right and S4.

The use of smart and self-assembled materials inspired from nature whose properties are dependent on external chemical or physical stimuli is emerging in biomedical field. ${ }^{[61]}$ The complex behavior of $\mathrm{Vmh} 2$ in ethanol/water solvents has been previously elucidated. ${ }^{[50]}$ Its aggregation can be controlled by environmental factors such as solvent polarity, temperature, divalent cations or base additon. ${ }^{[50]}$ Interestingly, we observed that the bio-hybrid GBM obtained by Vmh2 assisted exfoliation was endowed with the self-assembling characteristics of the protein moiety which enabled analogous handling of the material morphology. As solvent polarity was increased, by adding water to the water/ethanol solution, the $\mathrm{Vmh} 2$ assisted exfoliated GBMs reached the liquid-air or liquid-solid interface forming a homogeneous film (see Figure S5 and the video included as SI). Moreover, ammonia additions triggered the formation of Vmh2-GBM co-aggregated in solution, see Figure S5 right. All these results suggest the wide flexibility of this technology in adding value to carbon materials for an easy handling and applicability.

\subsection{Production of biofunctionalized GBMs}

We aim at contributing a cost-effective scalable process for the production of biofunctionalized graphene with well-defined characteristics. We optimized the process parameters to obtain the maximum yield $(\sim 45-50 \%)$ and production rate $\left(\sim 13-15 \mu \mathrm{g} \mathrm{mL}^{-1} \mathrm{~h}^{-1}\right)$ : exfoliation time $(5-7 \mathrm{~h})$, amount of starting material $\left(\sim 1 \mathrm{mg} \mathrm{mL}^{-1}\right)$, carbon/protein ratio (w/w 20:1), and Vmh2 concentration (50-100 $\left.\mu \mathrm{g} \mathrm{mL}^{-1}\right)$. Figure S6 summarizes the most relevant 


\section{WILEY-VCH}

parameters of the optimization process. Selection of GBMs classes on the base of particles size is easily and reliably achievable by controlled centrifugation. ${ }^{[60,62]}$ In particular, after removal of un-exfoliated material (40 minutes at $40 \mathrm{~g}$ ), consecutive $40 \mathrm{~min}$ centrifugations at increased centrifugal force were tested. Since it has been reported that the average number of monolayers per flakes reaches a minimum at $\sim 2500 \mathrm{~g},{ }^{[60]}$ we characterized the dispersions obtained after medium (620 g), and hard centrifugation (2500 g) steps, named MC and HC samples respectively. As expected, the applied centrifugal force dramatically influenced the GBMs yield in solution (see Figure 2A). SEM imaging proved an evident reduction of graphite micro-platelets and an improvement of homogeneity using both MC and HC (see Figure 2D showing SEM image of MC).

We also characterized the electrokinetic behavior of both MC and HC (see Figure S7). Pure Vmh2 protein in an electric field migrated towards the negative electrode in solution showing that the protein held a net positive charge, with an electrophoretic mobility $\left(U_{e}\right)$ of $0.55 \pm 0.06$ $\mu \mathrm{m} \mathrm{s}^{-1} \mathrm{~cm} \mathrm{~V}^{-1}$ (mean and standard error calculated on 10 sets of measurements). Moreover this value, increased in the presence of exfoliated graphene, up to $0.71 \pm 0.03 \mu \mathrm{m} \mathrm{s}^{-1} \mathrm{~cm} \mathrm{~V}^{-1}$ in the case of $\mathrm{HC}$ sample and up to $0.80 \pm 0.03 \mu \mathrm{m} \mathrm{s}^{-1} \mathrm{~cm} \mathrm{~V}^{-1}$ in the case of MC sample. Since the graphene surface is highly nonpolar this change suggested that new species were assembled upon mixing of protein and GBMs trough the adsorption of charged Vmh2 molecules onto the surface of carbon particles. The new molecular assemblies showed increased electrokinetic properties probably due to increased surface charge density and to the very unique solvent-sample relationship. We concluded that the interaction between graphene and the amphiphilic protein Vmh2 resulted in the formation of bio-hybrid assemblies endowed with a positive surface charge density. 


\section{WILEY-VCH}

The electrostatic repulsion generated by the protein coating could also explain the stabilization of graphene by $\mathrm{Vmh} 2$. Indeed, the estimation of $\zeta$-potential from electrophoretic mobility could assess the stability of the graphene dispersion through a model in which the

protein act as a surfactant. ${ }^{[22,23]}$ We could estimate the $\zeta$-potential of Vmh2 coated graphene flakes by the Henry equation (see experimental section). Considering the Huckel and Smoluchowski limits of the Henry function, we calculated both the lower and upper bounds of $\zeta$-potential. Values ranged between +40 and $+70 \mathrm{mV}$ for $\mathrm{Vmh} 2$ assisted exfoliated samples, classifying the biofunctionalized graphene as highly stable. ${ }^{[22]}$

Evidences of the Vmh2 coating on carbon particles were found out through AFM analysis of HC sample (see Figure 2E). On the basis of the height of the assembly in the AFM profiles and the expected diameter of a hydrophobin molecule $(\sim 3 \mathrm{~nm})$ we could assess that $\mathrm{Vmh} 2$ formed a discontinuous, one molecule thick coating. However, since the resolution on the XY plane was quite low because of the so called tip effect, the observed islands could be made of isolated Vmh2 monomers and/or oligomers.

In order to estimate the number of graphene layers per flake, as described below, we used Raman spectroscopy, since AFM analysis provides the top profile of the flakes while the structure of the lower layers is hidden.

\subsection{Raman spectroscopy characterization and classification of biofunctionalized graphene}

Currently, health risk associated to GBMs is under debate. ${ }^{[59,63,64]}$ Establishing the characteristics of the bio-functional graphene is essential to define the structure-safety relationship which is a future challenge concerning the use of graphene materials in biomedical applications. In order to avoid ambiguities in terms of characteristics of GBMs a 


\section{WILEY-VCH}

classification approach has been recently proposed. ${ }^{[59,65]}$ Such a nomenclature is based on the specification of the three most significant characteristics of the GBMs which modulate the chemical, physical and biological properties: number of graphene layers $\left(\mathrm{N}_{\mathrm{G}}\right)$; lateral size $(\mathrm{L}$, being rectangular-like structures, it generally refers to the maximum lateral dimension of the inspected flake) and defect type. Latest advances in Raman spectroscopy analysis have enabled a simple and consistent estimation of all these parameters.

Firstly, to investigate on the most important parameter, $\mathrm{N}_{\mathrm{G}}$, we fully capitalized on the Raman spectroscopy analysis recently proposed by Paton et al. 2014. ${ }^{[60]}$ Characteristics of the classic 2D band are associated with the stacking of carbon layers in GBM. The authors have developed a metric on the base of the consideration that the spectral intensity at the wavenumber corresponding to the $2 \mathrm{D}$ peak of graphite $\left(\omega_{\mathrm{p}}\right)$ and its shoulder $\left(\omega_{\mathrm{s}}=\omega_{\mathrm{p}}-30 \mathrm{~cm}^{-}\right.$ ${ }^{1}$ ) is strictly correlated to $\mathrm{N}_{\mathrm{G}}$, see details in experimental section. The result of the Raman analysis on the graphite spectrum (see Figure 3f) compared to those of some Vmh2 coated flakes demonstrated that few-layer graphene $\left(2 \div 5 \mathrm{~N}_{\mathrm{G}}\right)$ was produced (see Figure $\left.3 \mathrm{a}-\mathrm{e}\right)$.

Secondly, to check if the proposed process introduces damages, in the basal plane of graphene we studied defect-activated Raman signals, D $\left(\sim 1345 \mathrm{~cm}^{-1}\right)$ and the $\mathrm{D}^{\prime}\left(\sim 1620 \mathrm{~cm}^{-1}\right)$. Since the reduction of the flakes size determines an increase of the total boundaries, an intrinsic contribution to the D' band arises from edge type defects in exfoliated samples. Moreover graphite sources of different qualities could contain natural defects in the basal plane, i.e. sp3 and vacancy-like defects. Herein, the D band in spectra of crystallites we used for the synthesis of graphene was scarcely represented, so assessing the good quality of the starting material (Figure 3f). On the other hand, intense D signals were detected in the exfoliated flakes (Figure 3a-e). To check if Vmh2 based exfoliation introduced damages in 


\section{WILEY-VCH}

basal plane of graphene, we characterized the defect types analyzing the intensity ratio of the $\mathrm{D}$ and $\mathrm{D}^{\prime}$ peaks through Lorentzian fitting. ${ }^{[66]}$ According to Eckmann and colleagues, values of $\mathrm{D} / \mathrm{D}^{\prime} \sim 13$ indicated $\mathrm{sp}^{3}$ defects, $\mathrm{D} / \mathrm{D}^{\prime} \sim 7$ vacancy defects, $\mathrm{D} / \mathrm{D}^{\prime} \sim 3.5$ edge defects. The latter value has been revised by Paton et al. to include the error analysis: $3 \geq \mathrm{D} / \mathrm{D}^{\prime}$ edge defects $\geq 4.5 .^{[60]}$ All the calculated values of D/D' (Figure 3a-e) in our samples lied in the range indicated for edge type defects. It is worth noting that we set up the maximum ratio of ultrasonication power to reaction volume and the associated solvent heating was attenuated by ice bath cooling. Nevertheless, according to the data acquired experimentally using Raman, defects cannot be ascribed to the basal plane; hence we can conclude that no oxidation of graphene occurred in the course of exfoliation. This is likely due to the essential characteristics of the ultrawave exfoliation technique and to the protection of the $\mathrm{Vmh} 2$ coating against surface oxidation.

Thirdly, once demonstrated that only edge type defects were introduced during the exfoliation, Raman spectroscopy analysis enabled the estimation of graphene lateral size $(<\mathrm{L}>)$ through a metric based on the intensity ratio of the $\mathrm{D}$ and $\mathrm{G}$ peaks $(\mathrm{D} / \mathrm{G}),{ }^{[60,67,68]}$ (see details in experimental section). Spectra (Figure 3a-e) evidenced that the analyzed flakes were micro-sized. Interestingly, a positive correlation between $\left\langle\mathrm{N}_{\mathrm{G}}\right\rangle$ and $\langle\mathrm{L}\rangle$ was observed, although the two properties were estimated by the analysis of separate signals.

Finally, in order to unequivocally assess the quality of material, we performed a complete Raman analysis on 40 biofunctionalized flakes (see Figure 4), 16 from MC and 24 from HC sample. The $\left\langle\mathrm{N}_{\mathrm{G}}\right\rangle$ in both the samples laid in the $2 \div 5$ range, with an average value of $3.8 \pm$ 0.4 (standard error) layers in MC and of $2.9 \pm 0.3$ layers in HC. These data allowed the classification of both materials as few-layer graphene. ${ }^{[65]}$ Furthermore, on the base of the average lateral dimension, $1.0 \pm 0.1 \mu \mathrm{m}$ for $\mathrm{MC}, 0.49 \pm 0.06 \mu \mathrm{m}$ for $\mathrm{HC}$, we classified the 


\section{WILEY-VCH}

material as micro-graphene. Moreover the statistical distribution of $\left\langle\mathrm{N}_{\mathrm{G}}\right\rangle$ and $\langle\mathrm{L}\rangle$ data from all the 40 flakes confirmed their positive correlation (see Figure 4A). Then, the D/D' ratio data distribution definitely characterized the biofunctionalized graphene as defect free, hence lacking in functional groups of oxygen covalently bound to the basal plane (see Figure 4B). All these results are summarized in Table 1 putting into context both $\mathrm{MC}$ and $\mathrm{HC}$ materials as biofunctionalized defect-free few-layer micro-graphene.

\section{Conclusion}

We have demonstrated a method for the production of biofunctionalized defect-free GBMs by using a unique fungal protein, the hydrophobin $\mathrm{Vmh} 2$ extracted from the edible fungus Pleurotus ostreatus. Due to superior hydrophobicity and stability of $\mathrm{Vmh} 2$ we have obtained high concentration of GBMs $\left(\sim 440 \div 510 \mu \mathrm{g} \mathrm{mL}^{-1}\right)$ upon $\mathrm{Vmh} 2$ assisted exfoliation of raw graphitic material. Furthermore, we have proved through an accurate characterization that controlled centrifugation enables the selection of very stable $(>8$ months, $\zeta$-potential $+40 \div$ $+70 \mathrm{mV})$, few-layer $(<5$ layers $)$, defect-free graphene $\left(\sim 90 \div 100 \mu \mathrm{g} \mathrm{mL}^{-1}\right)$ with an average lateral dimension of $1.0 \pm 0.1 \mu \mathrm{m}$. Interestingly, the strong interplay between protein and graphene allows also the formation of either thin films on a silicon by the drop casting method or self-assembled bio-hybrid structures in solution by modulating the environmental conditions. As a potentially scalable approach, this method could enable massive production of biofunctionalized graphene, which could be a valuable material for the upcoming diffusion of new nano-biotechnologies in the global bio-medical market. ${ }^{[10,11]}$

\section{Experimental Section}

Vmh2 Extraction from P. ostreatus mycelia. White-rot fungus, P. ostreatus (Jacq.: Fr.) Kummer (type: Florida; ATCC No. MYA-2306) was maintained at $4{ }^{\circ} \mathrm{C}$ through periodic 


\section{WILEY-VCH}

transfer on potato dextrose agar (Difco) plates in the presence of $0.5 \%$ yeast extract. Mycelia were inoculated in $1 \mathrm{~L}$ flasks containing $500 \mathrm{~mL}$ of potato-dextrose broth $(24 \mathrm{~g} / \mathrm{L})$ supplemented with $0.5 \%$ yeast extract, grown at $28{ }^{\circ} \mathrm{C}$ in shaken mode $(150 \mathrm{rpm})$. After 10 days of fungal growth, mycelia were separated by filtration through gauze, treated twice with $2 \%$ SDS in a boiling water bath for $10 \mathrm{~min}$, washed several times with water and once with $60 \%$ ethanol to completely remove the detergent. The residue was dried under nitrogen, grinded and treated with $100 \%$ trifluoroacetic acid (TFA) in a water bath sonicator (Elmasonic S30, Elma) for $30 \mathrm{~min}$, and centrifuged (10 min at 3200g). The supernatant was dried, then lipids were extracted in a mixture of water-methanol-chloroform 2:2:1 v/v (5 min in bath sonicator). After centrifugation, proteins appeared as a solid aggregate at the interface between the water-methanol and the chloroform phases. They were recovered by liquid phase removal. The aggregated protein was dried, treated with TFA for $30 \mathrm{~min}$ in bath sonicator, redried, and dissolved in $80 \%$ ethanol. The sample was centrifuged (90 min at $12000 \mathrm{~g}$ ) and ethanol was removed from the supernatant under vacuum at $40{ }^{\circ} \mathrm{C}$ using rotavapor and the material was freeze-dried, treated with TFA as above-described and re-dissolved in $60 \%$ ethanol.

Exfoliation and Stabilization Process. Graphite powder (Aldrich, 332461, mesh number of grains $+100,>75 \%$ ) are exfoliated in batches of $5 \mathrm{~mL}$ of $60 \%$, v/v, ethanol in MilliQ water (in $10 \mathrm{~mL}$ flasks), 17-200 $\mu \mathrm{g} \mathrm{mL}^{-1} \mathrm{Vmh} 2$, using a medium power tip sonicator (Q125 Sonicator, QSonica, 125 Watt, 20kHz, inbuilt power meter power output, $19 \mathrm{~W}$ ) and cooling the system in an ice bath. Concentration of dispersions are estimated by UV-Vis spectroscopy. Absorption spectra are acquired on a UV-Vis spectrophotometer SpectraMax M2e using a quartz cell $1 \mathrm{~cm}$ optics. Upon the subtraction of the solvent spectrum we use the absorption coefficient value at $660 \mathrm{~nm}\left(1390 \mathrm{~g} \mathrm{~L} \mathrm{~cm}^{-1}\right)$ previously established by Lotya et. al. ${ }^{[22]}$ in a surfactant exfoliation process and also used in the hydrophobin-assisted exfoliation reported 


\section{WILEY-VCH}

by Laaksonen et al. ${ }^{[34]}$ Controlled centrifugation is performed using a Sigma 2-16PK FIsher Bioblock Scientific centrifuge (rotor 12072 418/H) in 15mL tubes.

HOPG (1000 ug mL $\left.\mathrm{mL}^{-1}\right)$ is exfoliated as previously described, for 2 hours in presence of Vmh2 protein $\left(50 \mu \mathrm{g} \mathrm{mL}^{-1}\right)$ and left to settling for 3 days to remove the unexfoliated material. Alternatively, HOPG is biofunctionalized immediatly after ultrasonication by mixing with a Vmh2 solution and treating 10 minutes in a bath sonicator (Fisherbrand, FB15051). A commercial GBM (Haydale, GNPs-O2) is resuspended in 6/4 (v/v) ethanol/MilliQ water solution, Vmh2 (50-400 $\left.\mu \mathrm{g} \mathrm{mL}^{-1}\right)$, sonicated 10 minutes in bath sonicator and used.

Characterization. SEM Scanning Electron Microscopy images are acquired using a FEI Quanta 650 FEG ESEM, $2 \mathrm{kV}$ microscope upon drop casting $3 \mu \mathrm{L}$ of solution on a silicon chip. AFM measurements are performed on mica using a Nanoscope V Multimode8 AFM (Bruker, Germany) and Si cantilevers (SNL model, k:0.3N/m, Bruker). The SFM are used at a scan rate of $1 \mathrm{~Hz}$ and 512 x 512 pixel.

Electrokinetic analysis is carried out in folded capillary cells using a Malvern Zetasizer Nano-ZS system equipped with a $633 \mathrm{~nm}$ He-Ne laser. The instrument uses a combination of electrophoresis and laser Doppler velocimetry techniques to measure the electrophoretic mobility $\left(\mathrm{U}_{\mathrm{e}}\right)$. All measurements are conducted at $25^{\circ} \mathrm{C}$.

$\zeta$-potential is estimated using the Henry equation:

$$
U_{\theta}=\frac{2}{3} \frac{\varepsilon \zeta}{\eta} f(k a)
$$

where $U_{e}$ is the electrophoretic mobility, $\varepsilon$ and $\eta$ are the dielectric constant and the viscosity of the solvent respectively, $\zeta$ is the $\zeta$-potential, and $f(k a)$ is the Henry function. Considering that the approximations for Henry function range between the Huckel and 


\section{WILEY-VCH}

Smoluchowski limits, $1 \div 1.5$, we estimate the upper and lower bound for the $\zeta$ potential.Raman spectra are acquired using a Horiba Jobin Yvon LabRAM HR 800, 800mm focal length, 100x objective, excitation wavelength 532nm. Exfoliated samples are drop casted for analysis on corning microscope glass slides (Aldrich, CLS294775X25), laser is focused on samples and multiple spectra are accumulated. For estimation of $\mathrm{N}_{\mathrm{G}}$ and $\mathrm{L}$ we use the Raman metrics reported by Paton et al.:[60]

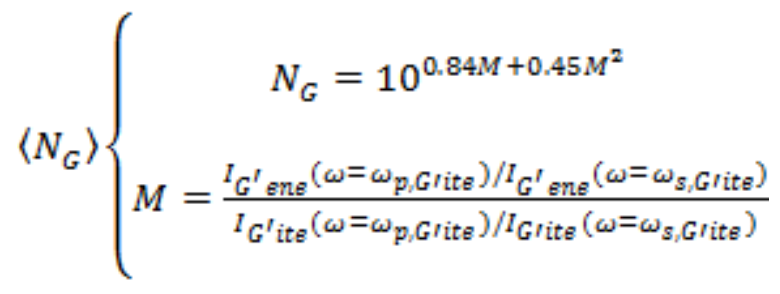

$\langle L\rangle\left\{\begin{array}{c}L=\frac{k}{(D / G)_{G^{\prime} \text { ene }}-(D / G)_{G^{\prime} \text { ite }}} \\ (D / G)_{G^{\prime} \text { ite }}=0.034 \\ k=0.17\end{array}\right.$

where $I_{G^{\prime}}^{r_{i t e}}\left(\omega=\omega_{p, G r i t e}\right)$ is the intensity of graphite $2 \mathrm{D}$ peak, $I_{\text {Grite }}\left(\omega=\omega_{s, \text { Grite }}\right)$ is the intensity of graphite 2D shoulder measured at $-30 \mathrm{~cm}^{-1}$ in respect to 2D peak (see Figure 3), $I_{G_{\text {ene }}^{r}}\left(\omega=\omega_{\text {p,Gite }}\right)$ is the intensity of graphene spectrum at the wavenumber corresponding to graphite 2D peak $\left(2717 \mathrm{~cm}^{-1}\right), I_{G^{\prime}{ }_{\text {ene }}}\left(\omega=\omega_{s_{3} \text { Grite }}\right)$ is the intensity of graphene spectrum at wavenumber corresponding to graphite $2 \mathrm{D}$ shoulder $\left(1686 \mathrm{~cm}^{-1}\right),\left(D / G_{G^{\prime} \text { ite }}\right.$ is the value of $\mathrm{D} / \mathrm{G}$ for graphite, and $k$ is the slope that has been estimated by Paton et al. for the same graphitic material.

\section{Supporting Information}




\section{WILEY-VCH}

Figures on a) Properties of hydrophobins relevant to carbon based materials interactions, b) Properties of Vmh2 relevant to carbon based materials interactions, c) Vmh2 assisted liquidphase exfoliation of HOPG, d) Vmh2 stabilization of GBMs, e) Self-assembled bio-hybrid structures, f) Graphene production assessment and g) Electrophoretic mobility distribution. h) video of the formation of a graphene layer at water-air interface are available as Supporting Information from the Wiley Online Library or from the author.

\section{Acknowledgements}

This work was supported by: The European Commission Program, FP7-OCEAN (613844) and MINECO (Spain; BIO2013-49464-EXP and RTC-2014-2619-7); Ministero dell'Università e della Ricerca Scientifica (Italy) - Industrial Research Project PON01_01966 EnerbioChem, funded in the frame of Operative National Programme Research and Competitiveness 2007-2013 D. D. Prot. n. 01/Ric. 18.1.2010; P.O.R. Campania FSE 20072013, Project CREMe. ICN2 acknowledges support from the Severo Ochoa Program (MINECO, Grant SEV-2013-0295). A.M. Gravagnuolo and E. Morales-Narváez contributed equally to this research.

Received: ((will be filled in by the editorial staff))

Revised: ((will be filled in by the editorial staff)) Published online: ((will be filled in by the editorial staff))

[1] A. K. Geim, Sci. 2009, 324, 1530.

[2] A. K. Geim, K. S. Novoselov, Nat Mater 2007, 6, 183.

[3] M. D. Stoller, S. Park, Y. Zhu, J. An, R. S. Ruoff, Nano Lett. 2008, 8, 3498.

[4] C. Lee, X. Wei, J. W. Kysar, J. Hone, Sci. 2008, 321 , 385.

[5] A. A. Balandin, S. Ghosh, W. Bao, I. Calizo, D. Teweldebrhan, F. Miao, C. N. Lau, Nano Lett. 2008, 8, 902.

[6] M. F. El-Kady, V. Strong, S. Dubin, R. B. Kaner, Sci. 2012, 335, 1326.

[7] R. R. Nair, P. Blake, A. N. Grigorenko, K. S. Novoselov, T. J. Booth, T. Stauber, N. M. R. Peres, A. K. Geim, Sci. 2008, 320, 1308.

[8] L. Gaudreau, K. J. Tielrooij, G. E. D. K. Prawiroatmodjo, J. Osmond, F. J. G. de Abajo, F. H. L. Koppens, Nano Lett. 2013, 13, 2030.

[9] J. S. Bunch, S. S. Verbridge, J. S. Alden, A. M. van der Zande, J. M. Parpia, H. G. Craighead, P. L. McEuen, Nano Lett. 2008, 8, 2458.

[10] A. C. Ferrari, F. Bonaccorso, V. Fal'ko, K. S. Novoselov, S. Roche, P. Bøggild, S. Borini, F. H. L. Koppens, V. Palermo, N. Pugno, J. A. Garrido, R. Sordan, A. Bianco, L. Ballerini, M. Prato, E. Lidorikis, J. Kivioja, C. Marinelli, T. Ryhänen, A. Morpurgo, J. N. Coleman, V. Nicolosi, L. Colombo, A. Fert, M. Garcia-Hernandez, A. Bachtold, G. F. Schneider, F. Guinea, C. Dekker, M. Barbone, Z. Sun, C. Galiotis, A. N. Grigorenko, G. Konstantatos, A. Kis, M. Katsnelson, L. Vandersypen, A. Loiseau, V. Morandi, D. Neumaier, E. Treossi, V. Pellegrini, M. Polini, A. Tredicucci, G. M. 


\section{WILEY-VCH}

Williams, B. H. Hong, J.-H. Ahn, J. M. Kim, H. Zirath, B. J. van Wees, H. van der Zant, L. Occhipinti, A. Di Matteo, I. A. Kinloch, T. Seyller, E. Quesnel, X. Feng, K. Teo, N. Rupesinghe, P. Hakonen, S. R. T. Neil, Q. Tannock, T. Löfwander, J. Kinaret, Nanoscale 2014.A. C. Ferrari, Nanoscale 2014, (Advance Article), DOI: 10.1039/C4NR01600A.

[11] Things you could do with graphene (Feature Article), Nat. Nanotechnol. 2014, 9, 737.

[12] E. Morales-Narváez, A.-R. Hassan, A. Merkoçi, Angew. Chemie Int. Ed. 2013, 52, 13779.

[13] E. Morales-Narváez, A. Merkoçi, Adv. Mater. 2012, 24, 3298.

[14] K. S. Novoselov, A. K. Geim, S. V Morozov, D. Jiang, Y. Zhang, S. V Dubonos, I. V Grigorieva, A. A. Firsov, Sci. 2004, $306,666$.

[15] K. S. Novoselov, V. I. Fal[prime]ko, L. Colombo, P. R. Gellert, M. G. Schwab, K. Kim, Nature 2012, 490, 192.

[16] R. S. Edwards, K. S. Coleman, Nanoscale 2013, 5, 38.

[17] S. Eigler, A. Hirsch, Angew. Chem. Int. Ed. Engl. 2014, 53, 7720.

[18] S. Park, R. S. Ruoff, Nat. Nanotechnol. 2009, 4, 217.

[19] G. Cravotto, P. Cintas, Chem. - A Eur. J. 2010, 16, 5246.

[20] S. Eigler, A. Hirsch, Angew. Chemie Int. Ed. 2014, 53, 7720.

[21] Y. Hernandez, M. Lotya, D. Rickard, S. D. Bergin, J. N. Coleman, Langmuir 2010, 26, 3208.

[22] M. Lotya, Y. Hernandez, P. J. King, R. J. Smith, V. Nicolosi, L. S. Karlsson, F. M. Blighe, S. De, Z. Wang, I. T. McGovern, G. S. Duesberg, J. N. Coleman, J. Am. Chem. Soc. 2009, 131, 3611.

[23] R. J. Smith, M. Lotya, J. N. Coleman, New J. Phys. 2010, 12, 125008.

[24] K. Yang, Y. Li, X. Tan, R. Peng, Z. Liu, Small 2013, 9, 1492.

[25] Y. Wang, Z. Li, J. Wang, J. Li, Y. Lin, Trends Biotechnol. 2011, 29, 205.

[26] C. Chung, Y.-K. Kim, D. Shin, S.-R. Ryoo, B. H. Hong, D.-H. Min, Acc. Chem. Res. 2013, 46, 2211.

[27] K. V. Krishna, C. Ménard-Moyon, S. Verma, A. Bianco, Nanomedicine (Lond). 2013, $8,1669$.

[28] T. S. Sreeprasad, V. Berry, Small 2013, 9, 341.

[29] M. Calvaresi, F. Zerbetto, Acc. Chem. Res. 2013, 46, 2454. 


\section{WILEY-VCH}

[30] C. Li, R. Mezzenga, Nanoscale 2013, 5, 6207.

[31] M. I. Solar, M. J. Buehler, Nat. Nanotechnol. 2012, 7, 417.

[32] C. Li, J. Adamcik, R. Mezzenga, Nat. Nanotechnol. 2012, 7, 421.

[33] W. Yang, Q. Ren, Y.-N. Wu, V. K. Morris, A. a Rey, F. Braet, A. H. Kwan, M. Sunde, Biopolymers 2013, 99, 84.

[34] P. Laaksonen, M. Kainlauri, T. Laaksonen, A. Shchepetov, H. Jiang, J. Ahopelto, M. B. Linder, Angew. Chemie Int. Ed. 2010, 49, 4946.

[35] Z. Wang, Y. Wang, Y. Huang, S. Li, S. Feng, H. Xu, M. Qiao, Carbon N. Y. 2010, 48, 2890 .

[36] K. Kurppa, H. Jiang, G. R. Szilvay, A. G. Nasibulin, E. I. Kauppinen, M. B. Linder, Angew. Chem. Int. Ed. Engl. 2007, 46, 6446.

[37] J. Bayry, V. Aimanianda, J. I. Guijarro, M. Sunde, J.-P. Latgé, PLoS Pathog. 2012, 8, e1002700.

[38] X. Wang, H. Wang, Y. Huang, Z. Zhao, X. Qin, Y. Wang, Z. Miao, Q. Chen, M. Qiao, Biosens. Bioelectron. 2010, 26, 1104.

[39] M. P. Sarparanta, L. M. Bimbo, E. M. Mäkilä, J. J. Salonen, P. H. Laaksonen, A. M. K. Helariutta, M. B. Linder, J. T. Hirvonen, T. J. Laaksonen, H. A. Santos, A. J. Airaksinen, Biomaterials 2012, 33, 3353.

[40] H. K. Valo, P. H. Laaksonen, L. J. Peltonen, M. B. Linder, J. T. Hirvonen, T. J. Laaksonen, ACS Nano 2010, 4, 1750.

[41] M. B. Linder, G. R. Szilvay, T. Nakari-Setälä, M. E. Penttilä, FEMS Microbiol. Rev. 2005, 29, 877 .

[42] H. J. Hektor, K. Scholtmeijer, Curr. Opin. Biotechnol. 2005, 16, 434.

[43] V. Aimanianda, J. Bayry, S. Bozza, O. Kniemeyer, K. Perruccio, S. R. Elluru, C. Clavaud, S. Paris, A. a Brakhage, S. V Kaveri, L. Romani, J.-P. Latgé, Nature 2009, $460,1117$.

[44] L. De Stefano, I. Rea, E. De Tommasi, I. Rendina, L. Rotiroti, M. Giocondo, S. Longobardi, a Armenante, P. Giardina, Eur. Phys. J. E. Soft Matter 2009, 30, 181.

[45] A. Zykwinska, M. Pihet, S. Radji, J.-P. Bouchara, S. Cuenot, Biochim. Biophys. Acta 2014, 1844, 1137.

[46] A. Zykwinska, T. Guillemette, J.-P. Bouchara, S. Cuenot, Biochim. Biophys. Acta 2014, 1844, 1231.

[47] I. Macindoe, A. H. Kwan, Q. Ren, V. K. Morris, W. Yang, J. P. Mackay, M. Sunde, Proc. Natl. Acad. Sci. U. S. A. 2012, 109, E804. 


\section{WILEY-VCH}

[48] V. K. Morris, Q. Ren, I. Macindoe, A. H. Kwan, N. Byrne, M. Sunde, J. Biol. Chem. 2011, 286, 15955.

[49] I. M. Tucker, J. T. Petkov, J. Penfold, R. K. Thomas, P. Li, A. R. Cox, N. Hedges, J. R. P. Webster, J. Phys. Chem. B 2014, 118, 4867.

[50] S. Longobardi, D. Picone, C. Ercole, R. Spadaccini, L. De Stefano, I. Rea, P. Giardina, Biomacromolecules 2012, 13, 743.

[51] A. Armenante, S. Longobardi, I. Rea, L. De Stefano, M. Giocondo, A. Silipo, A. Molinaro, P. Giardina, Glycobiology 2010, 20, 594.

[52] S. Houmadi, R. D. Rodriguez, S. Longobardi, P. Giardina, M. C. Fauré, M. Giocondo, E. Lacaze, Langmuir 2012, 28, 2551.

[53] L. De Stefano, I. Rea, P. Giardina, A. Armenante, I. Rendina, Adv. Mater. 2008, 20, 1529.

[54] I. Rea, P. Giardina, S. Longobardi, F. Porro, V. Casuscelli, I. Rendina, L. De Stefano, J. R. Soc. Interface 2012, 9, 2450.

[55] S. Longobardi, A. M. Gravagnuolo, R. Funari, B. Della Ventura, F. Pane, E. Galano, A. Amoresano, G. Marino, P. Giardina, Anal. Bioanal. Chem. 2014, 407, 487.

[56] L. De Stefano, I. Rea, A. Armenante, P. Giardina, M. Giocondo, I. Rendina, Langmuir 2007, 23, 7920 .

[57] V. Georgakilas, M. Otyepka, A. B. Bourlinos, V. Chandra, N. Kim, K. C. Kemp, P. Hobza, R. Zboril, K. S. Kim, Chem. Rev. 2012, 112, 6156.

[58] K. Kostarelos, K. S. Novoselov, Science 2014, 344, 261.

[59] P. Wick, A. E. Louw-Gaume, M. Kucki, H. F. Krug, K. Kostarelos, B. Fadeel, K. A. Dawson, A. Salvati, E. Vázquez, L. Ballerini, M. Tretiach, F. Benfenati, E. Flahaut, L. Gauthier, M. Prato, A. Bianco, Angew. Chemie Int. Ed. 2014, 53, 7714.

[60] K. R. Paton, E. Varrla, C. Backes, R. J. Smith, U. Khan, A. O’Neill, C. Boland, M. Lotya, O. M. Istrate, P. King, T. Higgins, S. Barwich, P. May, P. Puczkarski, I. Ahmed, M. Moebius, H. Pettersson, E. Long, J. Coelho, S. E. O’Brien, E. K. McGuire, B. M. Sanchez, G. S. Duesberg, N. McEvoy, T. J. Pennycook, C. Downing, A. Crossley, V. Nicolosi, J. N. Coleman, Nat Mater 2014, 13, 624.

[61] E. Lurie-Luke, Biotechnol. Adv. 2014, 32, 1494.

[62] U. Khan, A. O’Neill, H. Porwal, P. May, K. Nawaz, J. N. Coleman, Carbon N. Y. 2012, 50,470 .

[63] A. Bianco, Angew. Chem. Int. Ed. Engl. 2013, 52, 4986.

[64] Y. Ma, H. Shen, X. Tu, Z. Zhang, Nanomedicine (Lond). 2014, 9, 1565. 


\section{WILEY-VCH}

[65] A. Bianco, H.-M. Cheng, T. Enoki, Y. Gogotsi, R. H. Hurt, N. Koratkar, T. Kyotani, M. Monthioux, C. R. Park, J. M. D. Tascon, J. Zhang, Carbon N. Y. 2013, 65, 1.

[66] A. Eckmann, A. Felten, A. Mishchenko, L. Britnell, R. Krupke, K. S. Novoselov, C. Casiraghi, Nano Lett. 2012, 12, 3925.

[67] A. O’Neill, U. Khan, P. N. Nirmalraj, J. Boland, J. N. Coleman, J. Phys. Chem. C 2011, 115, 5422.

[68] U. Khan, A. O’Neill, M. Lotya, S. De, J. N. Coleman, Small 2010, 6, 864.

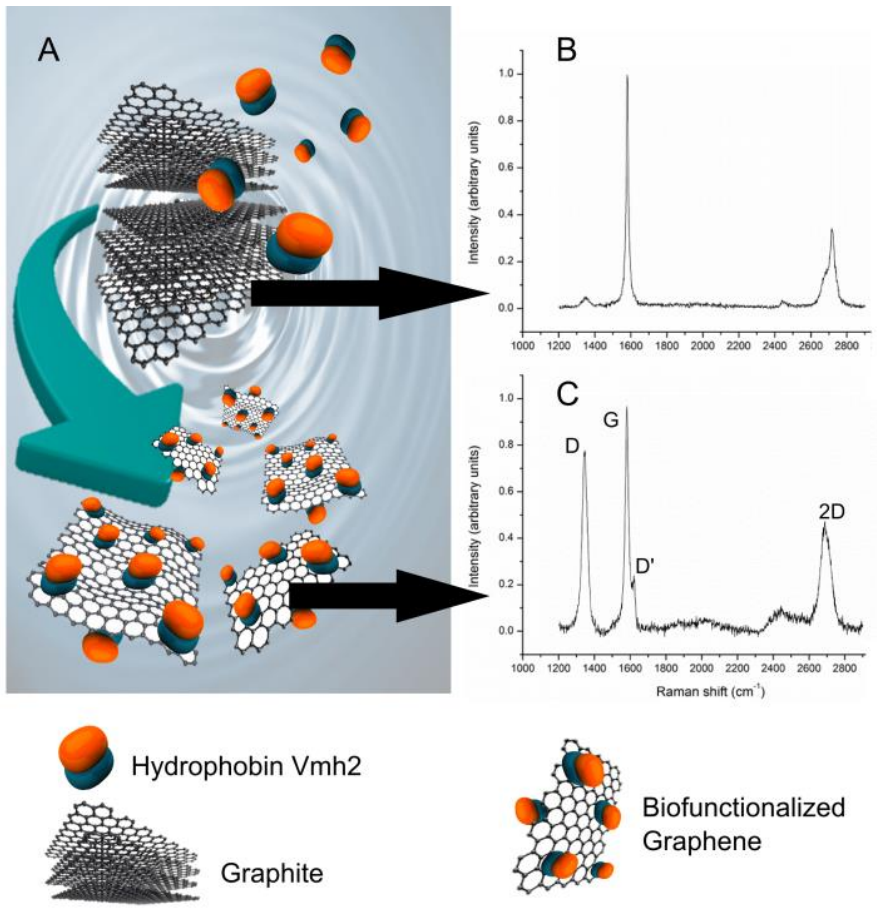

Figure 1. In situ generation of biofunctionalized graphene. (A) Schematic representation of the process. Ultrasound waves are applied as a source of mechanical force that brakes and exfoliates the starting material (graphite). Subsequently, the hydrophobic region of the amphiphilic protein hydrophobin $\mathrm{Vmh} 2$ is spontaneously adsorbed onto the laminated material (which is also hydrophobic) stabilizing and functionalizing the exfoliated material. (B) Raman spectra of the starting material (graphite crystallites). (C) Raman spectra of the generated material (biofunctionalized few-layer graphene flake). Experimental conditions as given in the text. 


\section{WILEY-VCH}
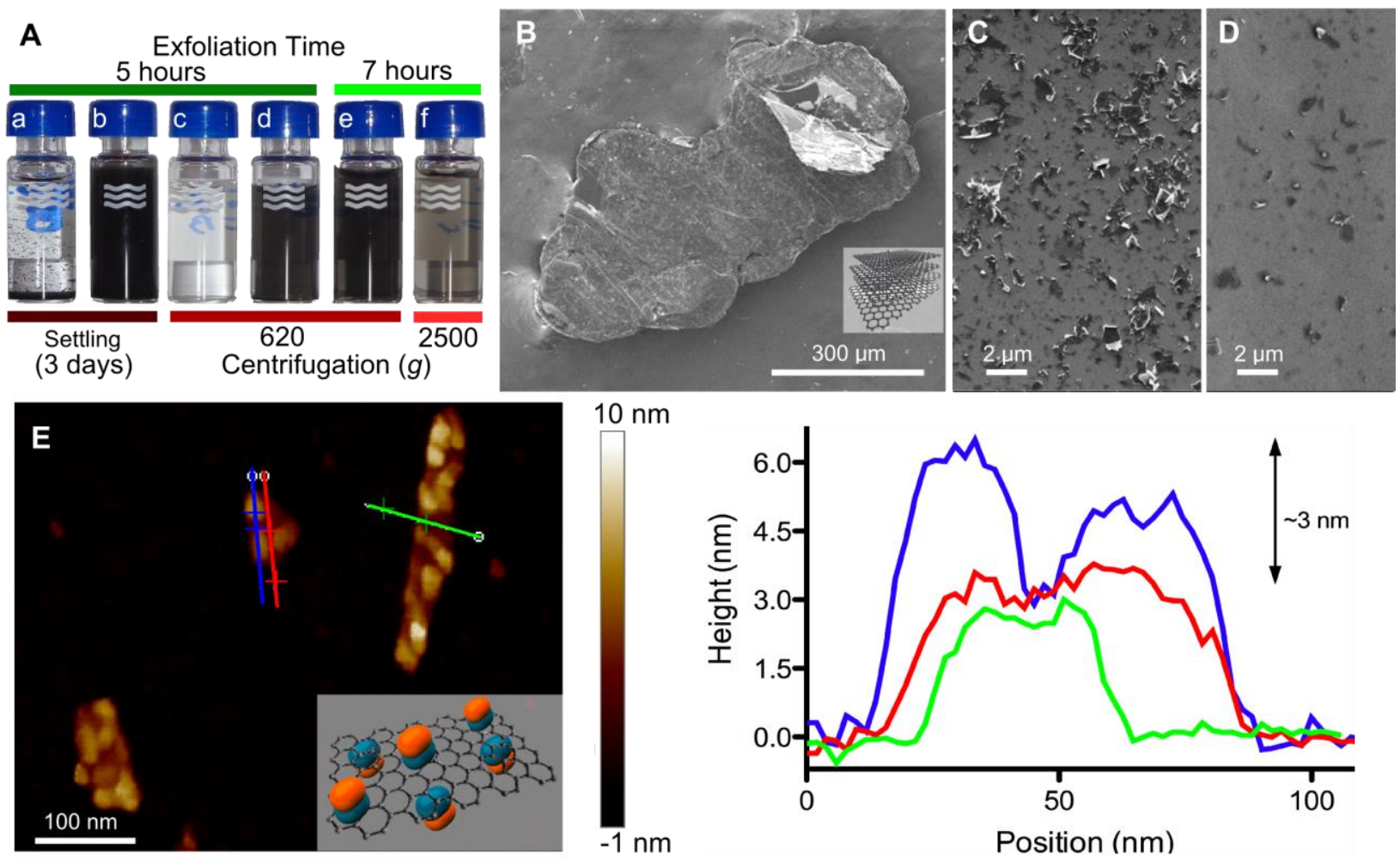

Figure 2. Production of Biofunctionalized Graphene. (A, a-f) Samples of the dispersions obtained through $(\mathrm{a}, \mathrm{c})$ liquid phase exfoliation in absence of $\mathrm{Vmh} 2$ and $(\mathrm{b}, \mathrm{d}, \mathrm{e}, \mathrm{f}) \mathrm{Vmh} 2$ assisted exfoliation. (B) SEM image of the starting material (graphite flake). (C) SEM image of the dispersion shown in (A, b). (D) SEM image of the dispersion displayed in $(A, d)$. (E, left) AFM analysis of biofunctionalized graphene obtained from the sample HC shown in (A, f). (E, right) AFM profiles of 2 flakes showing the graphene-Vmh2 assembly. Experimental conditions as given in the text. 


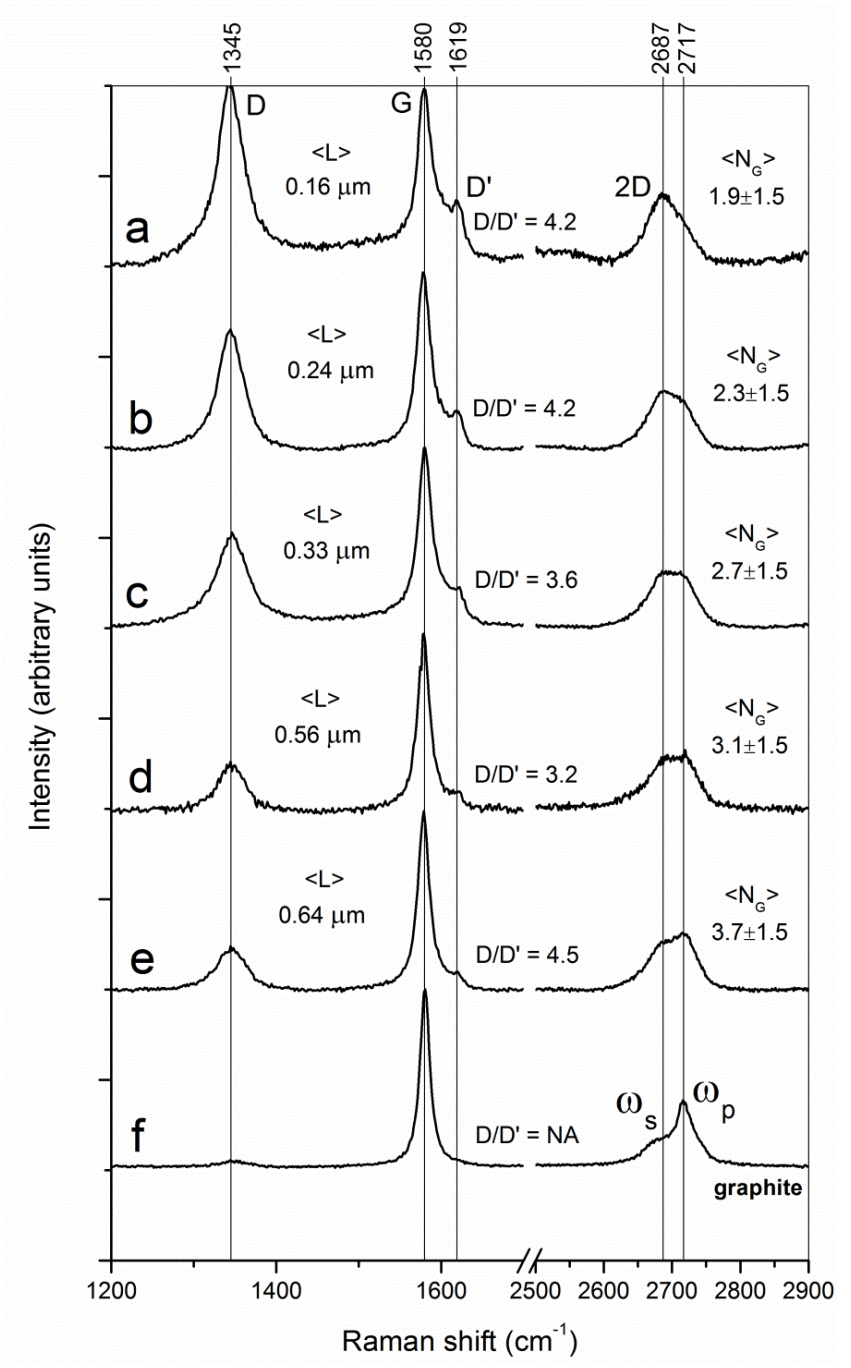

Figure 3. Quality assessment by Raman spectroscopy analysis of (a,b,c,d,e,) biofunctionalized flakes of increasing sizes (from HC sample) and of (f) graphite, i.e. the starting material, indicating the wavenumbers corresponding to $D, G, D^{\prime}, 2 D$ peak of graphite $\left(\omega_{\mathrm{p}}\right)$ and its shoulder $\left(\omega_{\mathrm{s}}=\omega_{\mathrm{p}}-30 \mathrm{~cm}^{-1}\right)$ and the estimated lateral dimension $\left.(<\mathrm{L}\rangle\right), \mathrm{D} / \mathrm{D}^{\prime}$ ratio obtained by fitting and estimated number of graphene layers $\left(\left\langle\mathrm{N}_{\mathrm{G}}\right\rangle\right)$. Experimental conditions as given in the text. 


\section{WILEY-VCH}
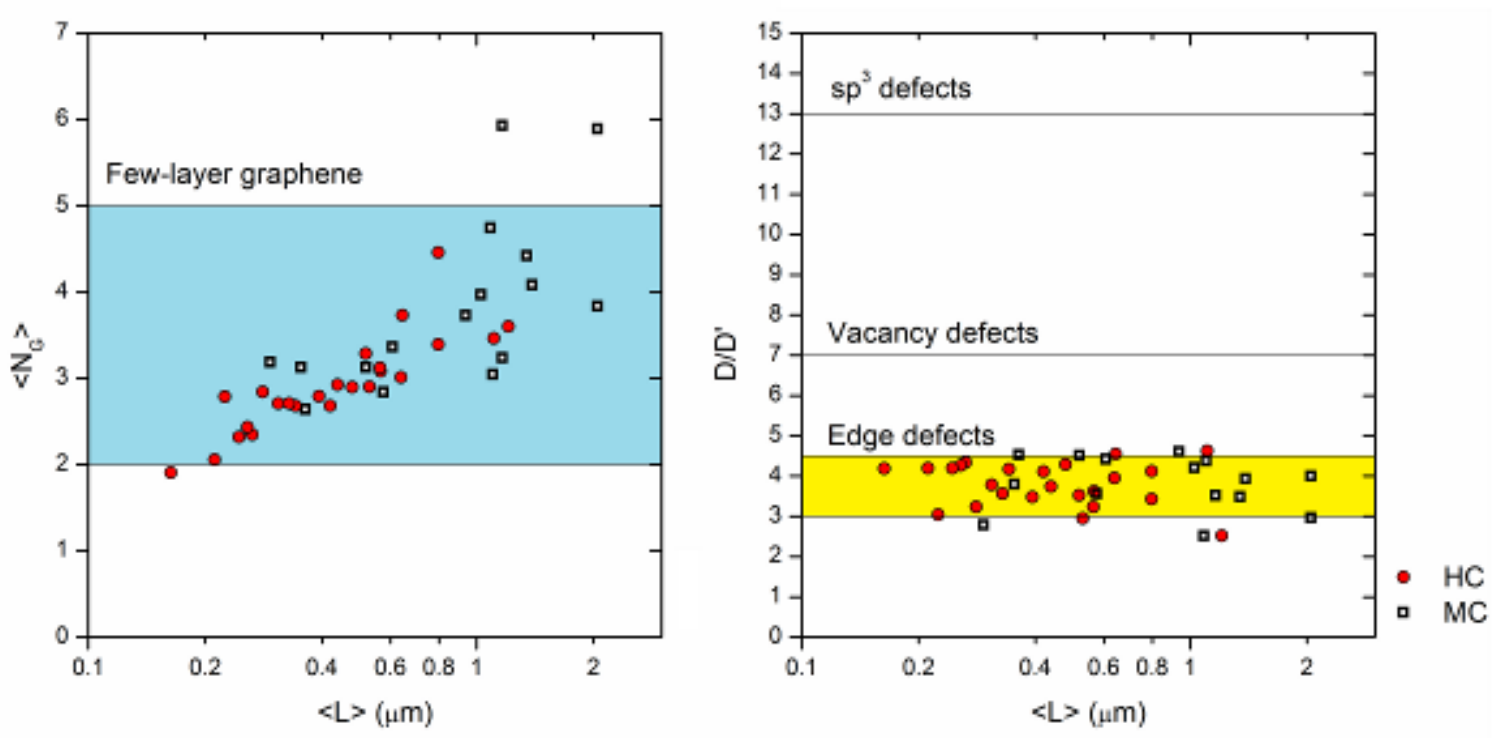

Figure 4. Statistical distribution of (left) the $\left\langle\mathrm{N}_{\mathrm{G}}\right\rangle$ and (right) the $\mathrm{D} / \mathrm{D}$ ' ratio, in $\mathrm{MC}$ and $\mathrm{HC}$ samples used for GBM classification. Experimental conditions as given in the text. 
Table 1. Summary of MC and HC samples characteristics.

\begin{tabular}{|c|c|c|c|}
\hline Graphene property & Type of analysis & $M C$ & $H C$ \\
\hline Average $<\mathrm{N}_{\mathrm{G}}>$ & Raman; 2D based metric ${ }^{60}$ & $3.8 \pm 0.4$ layers & $2.9 \pm 0.3$ layers \\
\hline Average $<\mathrm{L}>$ & Raman; D/G based metric ${ }^{60}$ & $1.0 \pm 0.1 \mu \mathrm{m}$ & $0.49 \pm 0.06 \mu \mathrm{m}$ \\
\hline \multirow[t]{3}{*}{ Defect type/oxidation } & $\begin{array}{l}\text { Raman D/D' based } \\
\text { classification }{ }^{60,66}\end{array}$ & $\mathrm{D} / \mathrm{D}^{\prime} 3.8 \pm 0.2$ & $\mathrm{D} / \mathrm{D}^{\prime} 3.8 \pm 0.1$ \\
\hline & & Edge type defects & Edge type defects \\
\hline & & Not oxidized & Not oxidized \\
\hline \multirow[t]{2}{*}{ Biofunctionalization } & AFM & Vmh2 monolayer & Vmh2 monolayer \\
\hline & Electrophoretic Mobility & $\begin{array}{l}\text { Positive surface charge } \\
\text { density }\end{array}$ & $\begin{array}{l}\text { Positive surface charge } \\
\text { density }\end{array}$ \\
\hline \multirow[t]{2}{*}{ Stability } & Time & $>8$ Months & $>8$ months \\
\hline & $\zeta$-potential ${ }^{22}$ & $+40 \div+70 \mathrm{mV}$ & $+40 \div+70 \mathrm{mV}$ \\
\hline Concentration & UV-Vis spectroscopy ${ }^{22,34}$ & $90 \div 100 \mu \mathrm{g} \mathrm{mL}^{-1}$ & $20 \div 30 \mu \mathrm{g} \mathrm{mL}^{-1}$ \\
\hline
\end{tabular}

Analysis of $\mathrm{MC}$ and $\mathrm{HC}$ performed on 16 and 24 individual flakes respectively and reported for each parameter as mean \pm standard error. The standard error of $\left\langle\mathrm{N}_{\mathrm{G}}\right\rangle$ was calculated on the base of a fix error of \pm 1.5 on the single measurements. 


\section{WILEY-VCH}

Biofunctionalized defect-free few-layer micro-graphene sheets can be obtained using liquid phase ultrasonic exfoliation of raw graphitic material assisted by the self-assembling fungal hydrophobin Vmh2. This approach enables a highly concentrated and stable exfoliated product, $\sim 440-510 \mu \mathrm{g} \mathrm{mL}-1$ ( $\zeta$-potential, $+40 \div+70 \mathrm{mV}$ ). The obtained material is likely to prove valuable for the emerging applications of graphene in the biotechnological field such as sensing and drug delivery.

\section{Biofunctionalized Graphene}

A.M. Gravagnuolo, E. Morales-Narváez, E. T. da Silva, S. Longobardi, P. Giardina, Arben Merkoçi*

In situ Production of Biofunctionalized Few-Layer Defect-Free Microsheets of GrapheneTitle

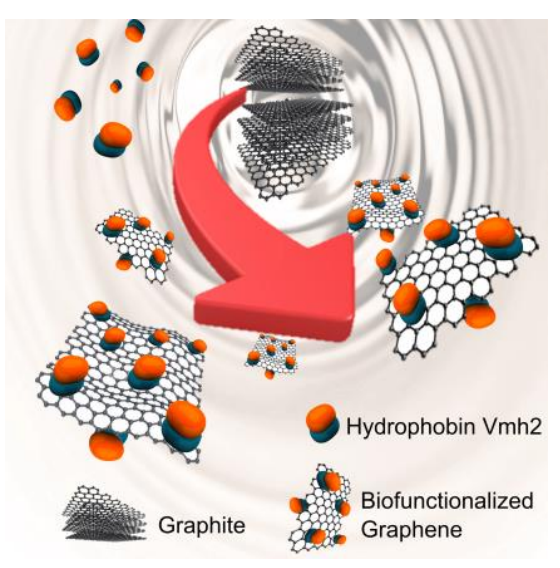

ToC figure 


\section{WILEY-VCH}

Copyright WILEY-VCH Verlag GmbH \& Co. KGaA, 69469 Weinheim, Germany, 2015.

\section{Supporting Information}

In situ Production of Biofunctionalized Few-Layer Defect-Free Microsheets of Graphene

Alfredo M. Gravagnuolo ${ }^{*}$ Eden Morales-Narváez ${ }^{*}$ Sara Longobardi, Everson T. da Silva, Paola Giardina and Arben Merkoçi*

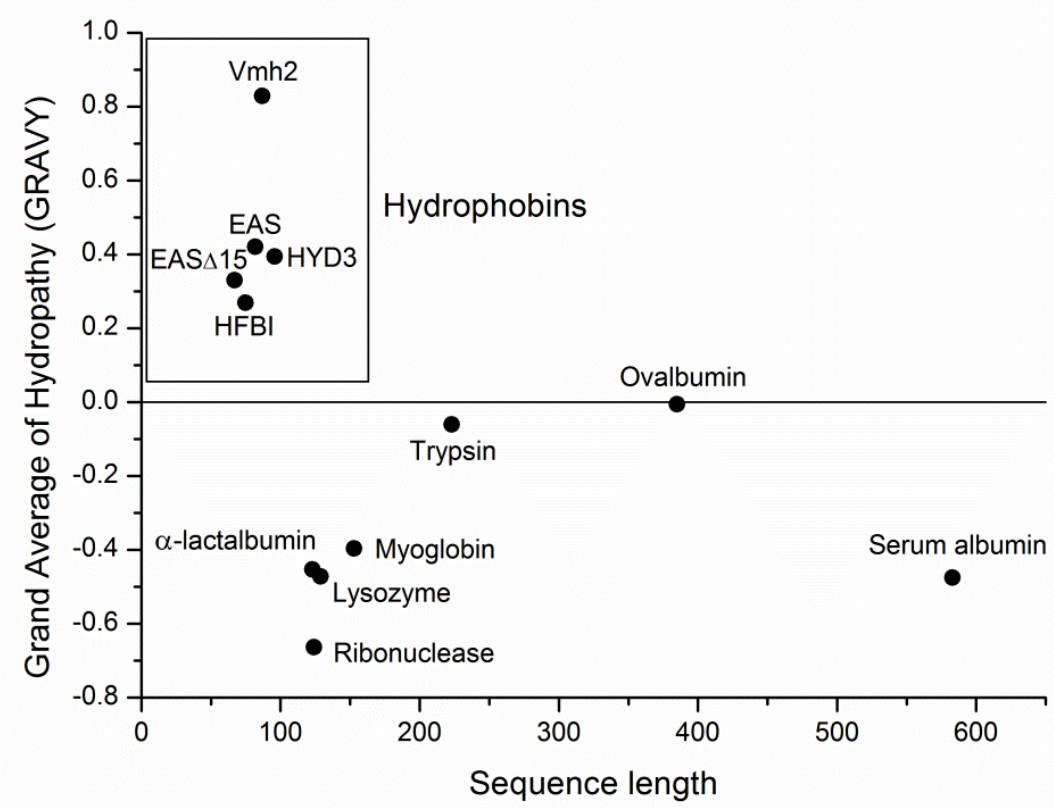

Figure S1. Properties of hydrophobins relevant to carbon based materials interactions. Hydropathic character of some soluble proteins, included hydrophobins that have been used to functionalize carbon based materials. GRAVY index is evaluated on the basis of amino acid composition and Kyte \& Doolittle scale. ${ }^{1}$ 


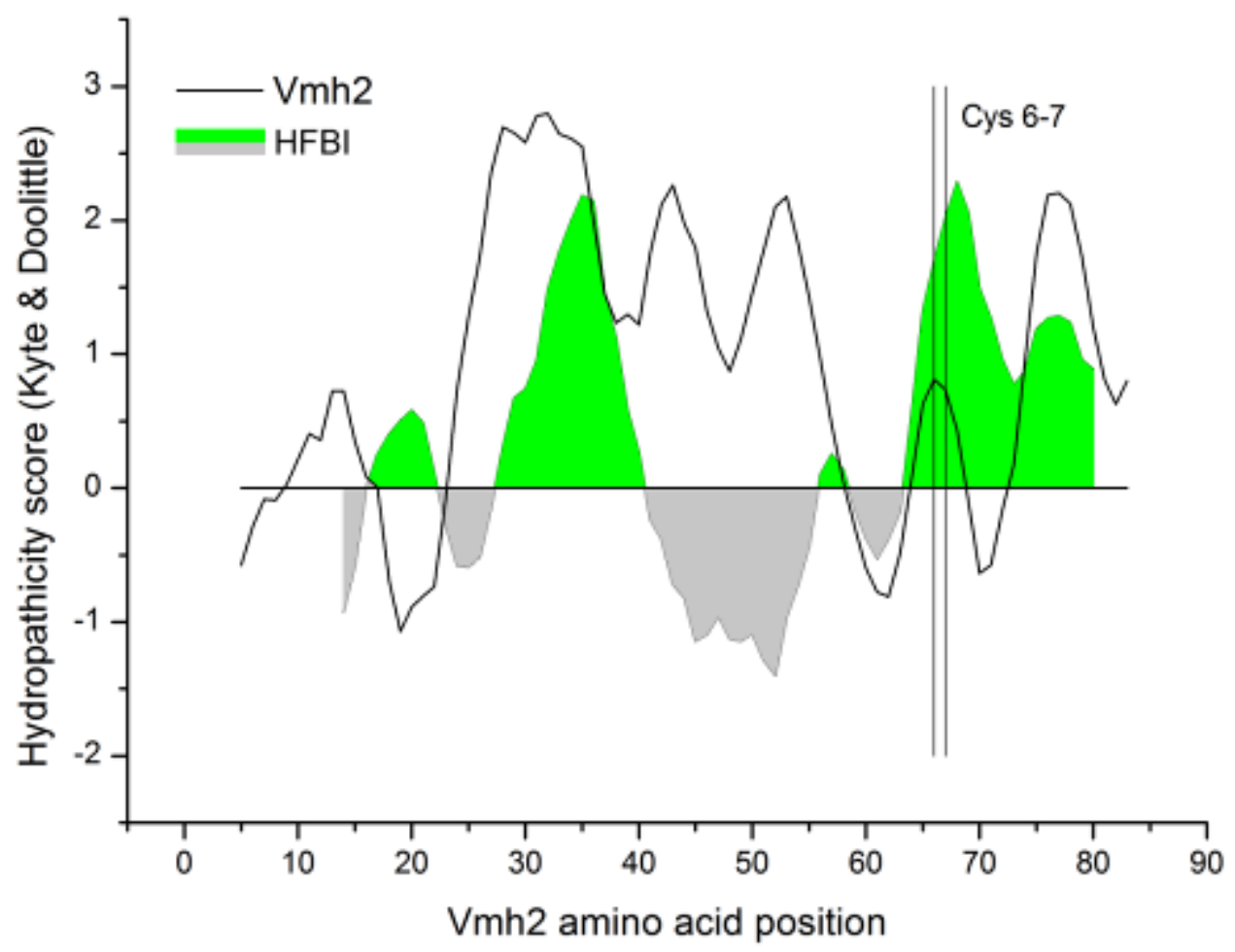

Figure S2. Properties of Vmh2 relevant to GBMs interactions. Hydropathicity pattern of Vmh2 (UniProt ${ }^{2}$ Accession Number Q8WZI2; chain 25-111) and HFBI (UniProt Accession Number P52754; chain 23-97) displayed by Prot Scale ${ }^{1}$ (parameters: Kyte \& Doolittle amino acid scale; 9 amino acids windows size; $20 \%$ relative weight of the window edges; linear weight variation model). 


\section{WILEY-VCH}
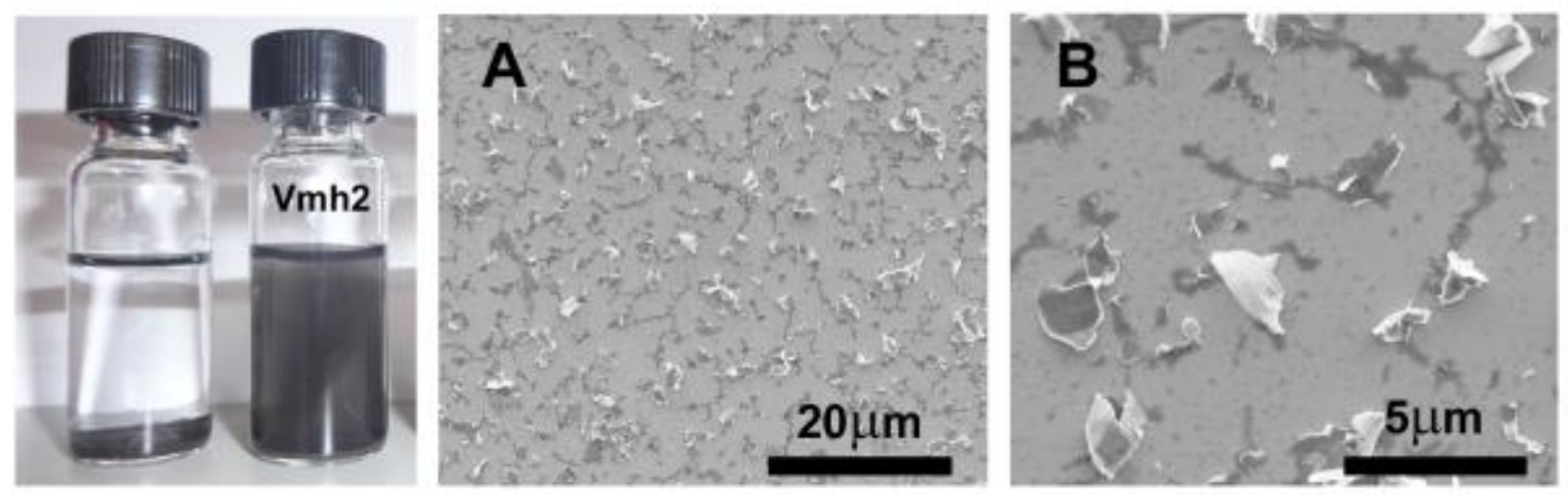

Figure S3. Vmh2 assisted liquid-phase exfoliation of HOPG. (left) Samples of HOPG exfoliated for 2 hours in the presence or absence of Vmh2 and kept to settle out for 3 days. (A, B) HOPG-Vmh2 coating of a silicon chip obtained by drop casting. Experimental conditions as given in the text. 


\section{WILEY-VCH}
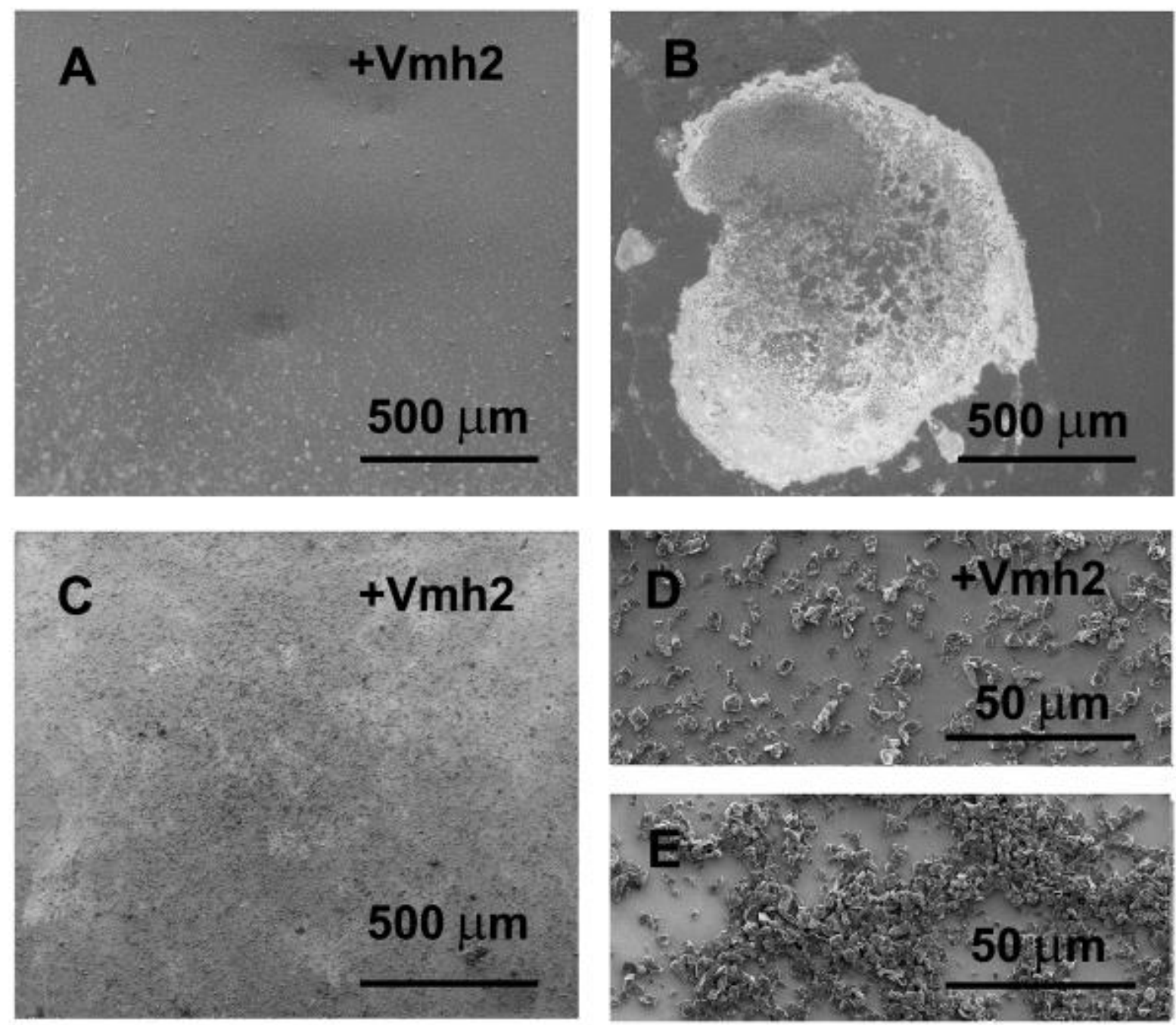

Figure S4. Vmh2 stabilization of GBMs. (A) Silicon chip coated by drop casting with HOPG biofunctionalized after exfoliation. (B) Silicon chip coated with HOPG as in (A) but in the absence of Vmh2. (C, D) Silicon chip coated with a commercial GBM powder stabilized by mixing with Vmh2. (E) Silicon chip coated as in $(C, D)$ using the commercial GBM in the absence of $\mathrm{Vmh} 2$.-Experimental conditions as given in the text 


\section{WILEY-VCH}
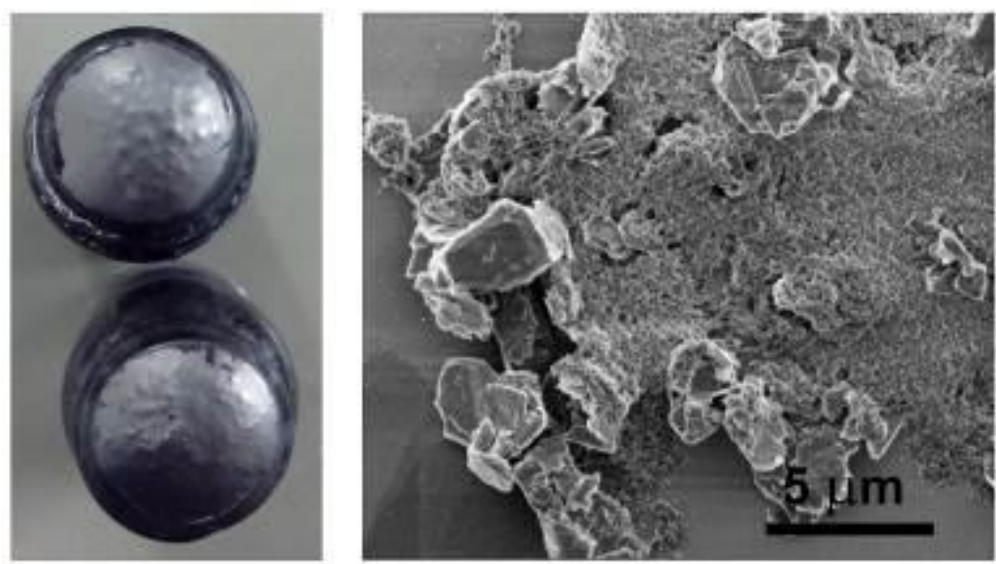

Figure S5. Self-assembled bio-hybrid structures. (Left) Exfoliated Vmh2-GBM at liquidair interface upon lowering the solvent polarity by water addition (Right) Vmh2-commercial GBM co-aggregate, assembled upon ammonia addition. 


\section{WILEY-VCH}

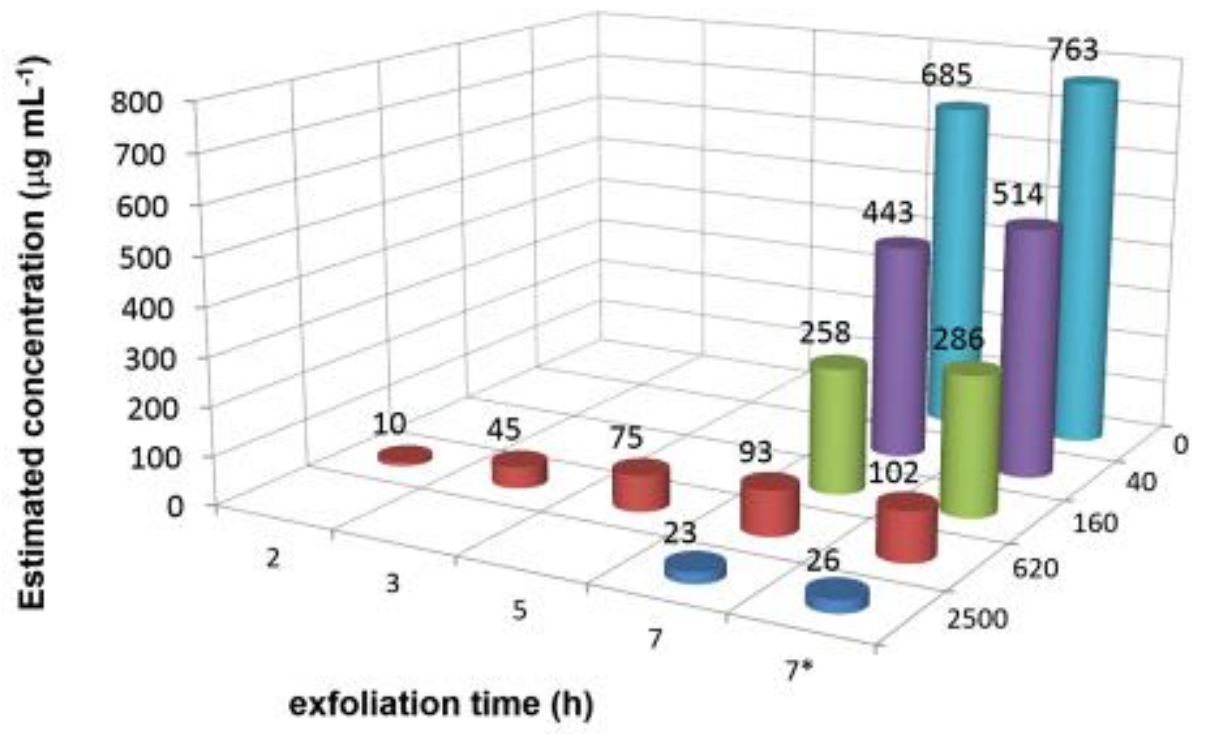

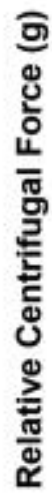

Figure S6. Graphene production assessment. Optimization of the production process by using: graphite flakes $1 \mathrm{mg} \mathrm{mL}^{-1} ; \mathrm{Vmh}^{2} 50 \mathrm{ug} \mathrm{mL}^{-1} ; 60 \%(\mathrm{v} / \mathrm{v})$ ethanol in water solution. (7*) effect of using double amounts of starting material $(2 \mathrm{mg} / \mathrm{mL})$ and $\mathrm{Vmh} 2\left(100 \mu \mathrm{g} \mathrm{mL}^{-1}\right)$. 


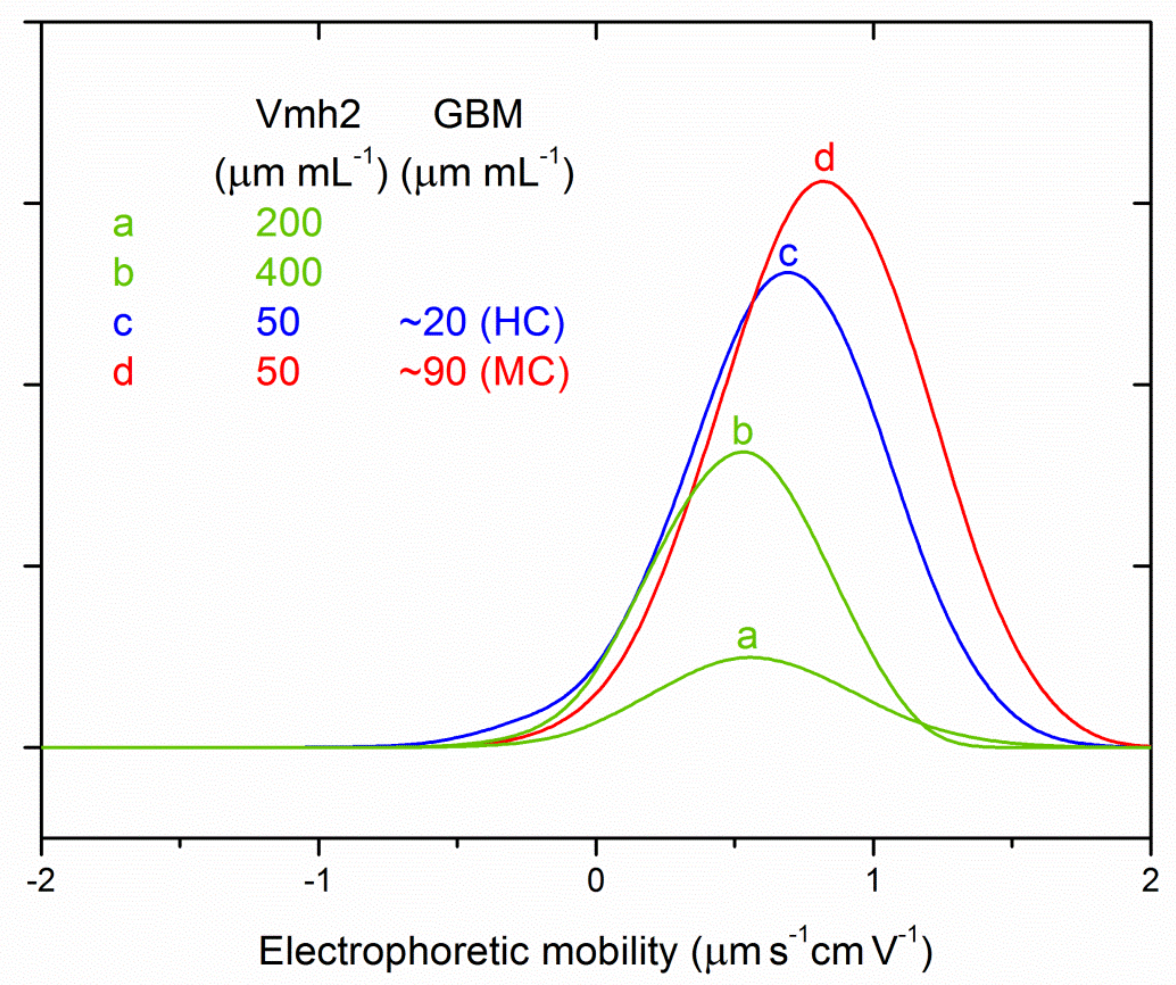

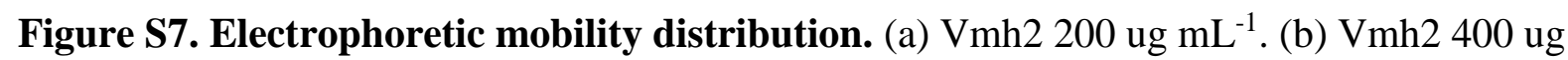
$\mathrm{mL}^{-1}$ (c) HC sample; Vmh2 $50 \mathrm{ug} \mathrm{mL} \mathrm{m}^{-1}$, few layer graphene $20 \mathrm{ug} \mathrm{mL}^{-1}$. (d) MC sample; $\mathrm{Vmh} 250 \mathrm{ug} \mathrm{mL}^{-1}$, few layer graphene $\sim 90 \mathrm{ug} \mathrm{mL}^{-1}$. Since the signal intensity of $\mathrm{Vmh} 2$ sample was too low at the concentration used for exfoliation, measurements were perforemd at higher concentrations $(\mathrm{a}, \mathrm{b})$ 


\section{WILEY-VCH}

Table S1. Comparison of Hydrophobin assisted exfoliations proposed by Laaksonen $e t$ al. 2010. Process parameters used for the production of biofunctionalized graphene at the best of their yield.

\begin{tabular}{|c|c|c|}
\hline & This work & Laaksonen et al. $2010^{3}$ \\
\hline Hydrophobin & $\begin{array}{l}\text { Vmh2 from Pleurotus ostreatus }(50 \div 100 \mu \mathrm{g} \\
\left.\mathrm{mL}^{-1}\right)\end{array}$ & $\begin{array}{l}\text { HFBI from Trichoderma reesei }(25 \div 2000 \mu \mathrm{g} \\
\left.\mathrm{mL}^{-1}\right)\end{array}$ \\
\hline Graphite source & Graphite powder $\left(1000-2000 \mathrm{mg} \mathrm{mL}^{-1}\right)$ & $\begin{array}{l}\text { Chemically purified Kish graphite (amount not } \\
\text { available) }\end{array}$ \\
\hline Solvent & $60 \%, v / v$, ethanol in MilliQ water & MilliQ water \\
\hline Tip Sonicator & $\begin{array}{l}\text { Q125 Sonicator, QSonica, } 125 \text { Watt, } 20 \mathrm{kHz} \text {. } \\
\text { Inbuilt power meter power output = } 19 \mathrm{~W}\end{array}$ & $\begin{array}{l}\text { Vibra-Cell VCX } 750 \text {, Sonics \& Materials Inc., } 750 \\
\text { Watt, } 20 \mathrm{KHz}\end{array}$ \\
\hline Reaction volume & $5 \mathrm{~mL}$ & $0,3 \div 1 \mathrm{~mL}$ \\
\hline Exfoliation Time & 7 hours in presence of $\mathrm{Vmh} 2$ & $\begin{array}{l}2 \text { minutes in absence of } \mathrm{HFBI} \text { and } 2 \text { minutes in } \\
\text { presence of } \mathrm{HFBI}\end{array}$ \\
\hline $\begin{array}{l}\text { Removal of un-exfoliated } \\
\text { material }\end{array}$ & $\begin{array}{l}40 \text { min at } 40 \mathrm{~g} \text { using a Sigma } 2-16 \mathrm{PK} \text { Flsher } \\
\text { Bioblock Scientific centrifuge (rotor } 12072 \\
418 / \mathrm{H} \text { ) }\end{array}$ & $\begin{array}{l}\text { Gentle centrifugation using a National Labnet } \\
\text { Co., Mini centrifuge C- } 1200\end{array}$ \\
\hline Yield & $\sim 440 \div 510 \mu \mathrm{g} \mathrm{mL}^{-1}$ & $\sim 25 \div 40 \mu \mathrm{g} \mathrm{mL}^{-1}$ \\
\hline
\end{tabular}




\section{WILEY-VCH}

\section{SUPPORTING REFERENCES}

[1] E. Gasteiger, C. Hoogland, A. Gattiker, S. Duvaud, M. R. Wilkins, R. D. Appel, A. Bairoch, In The Proteomics Protocols Handbook; Walker, J. M., Ed.; Humana Press: Totowa, NJ, 2005; pp. 571-607.

[2] The UniProt Consortium, Nucleic Acids Res. 2014, 42, D191.

[3] P. Laaksonen, M. Kainlauri, T. Laaksonen, A. Shchepetov, H. Jiang, J. Ahopelto, M. B. Linder, Angew. Chemie Int. Ed. 2010, 49, 4946. 